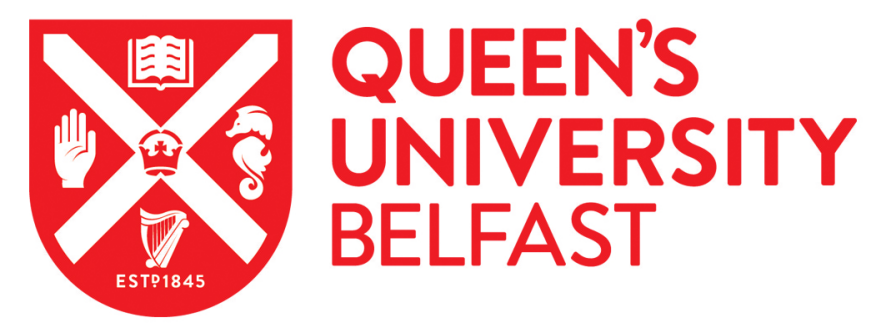

\title{
Experimental and numerical study of fastener pull-through failure in GFRP laminates
}

Catalanotti, G., Camanho, P. P., Ghys, P., \& Marques, A. T. (2011). Experimental and numerical study of fastener pull-through failure in GFRP laminates. Composite Structures, 94(1), 239-245.

https://doi.org/10.1016/j.compstruct.2011.06.021

\section{Published in:}

Composite Structures

\section{Document Version:}

Peer reviewed version

\section{Queen's University Belfast - Research Portal:}

Link to publication record in Queen's University Belfast Research Portal

\section{Publisher rights}

Copyright 2011 Elsevier

This manuscript is distributed under a Creative Commons Attribution-NonCommercial-NoDerivs License

(https://creativecommons.org/licenses/by-nc-nd/4.0/), which permits distribution and reproduction for non-commercial purposes, provided the author and source are cited.

\section{General rights}

Copyright for the publications made accessible via the Queen's University Belfast Research Portal is retained by the author(s) and / or other copyright owners and it is a condition of accessing these publications that users recognise and abide by the legal requirements associated with these rights.

Take down policy

The Research Portal is Queen's institutional repository that provides access to Queen's research output. Every effort has been made to ensure that content in the Research Portal does not infringe any person's rights, or applicable UK laws. If you discover content in the Research Portal that you believe breaches copyright or violates any law, please contact openaccess@qub.ac.uk. 


\title{
Experimental and numerical study of fastener pull-through failure in GFRP laminates
}

\author{
G. Catalanotti ${ }^{\text {a,* }}$, P.P. Camanho ${ }^{\text {a }}$, P. Ghys ${ }^{\text {b }}$, A.T. Marques ${ }^{\text {a }}$ \\ ${ }^{a}$ DEMec, Faculdade de Engenharia, Universidade do Porto, Rua Dr. Roberto \\ Frias, 4200-465, Porto, Portugal \\ ${ }^{\mathrm{b}}$ ALSTOM Transport, Rue Albert Dhalenne, 48, 93482, Saint-Ouen, France
}

\begin{abstract}
An experimental and numerical study of the fastener pull-through failure mode in glass-fiber reinforced plastic (GFRP) laminates using both phenolic and vinylester resins is presented. It is shown that the type of resin does not affect the mechanical response of the joint when a pull-through test is performed because similar values of the sub-critical initial and final failure loads are obtained. Moreover, considering that the joint is considering to fail when the sub-critical failure load is reached, a methodology to predict the pull-through failure mode is proposed. It is observed that the main failure mechanism is the delamination of the plies; therefore, the prediction of the sub-critical initial failure load is performed using a three-dimensional finite element model where cohesive elements are used to simulate delamination. The predictions agree remarkably well with the experimental results.
\end{abstract}

Key words: A. Hybrid structures, B. Bolted joints, C. Pull-through

\footnotetext{
* Corresponding author

Email address: giuseppe.catalanotti@fe.up.pt (G. Catalanotti).
} 


\section{Introduction}

GFRP laminates are used in marine, railway and automotive industries in nonstructural parts and, more recently, in the main load-carrying structures. The use of composites leads to a reduction of the weight (and consequently of the cost of the transportation), a reduction of manufacturing costs (simplification of the design and reduction of the costs required for the assembly), and to a reduction of the recurring cost (composites require less maintenance than metals).

Due to their high specific stiffness and strength and to the flexibility in their use, GFRP are nowadays used together with metals in the design of hybrid low-cost train structures [1]. Hybrid structures are interesting for the railway industry because they may result in a mass reduction of about $12-24 \%$ and in a cost reduction of about $20 \%$ [2]. One of the main design requirements of the railway industry is the calculation of the strength of hybrid bolted joints, which correspond to the critical regions of the structures.

While the prediction of the strength of composite bolted joints under in-plane failure mechanism has been throughly investigated in the literature [3-7], few attempts have been made to predict out-of-plane failure mechanism, such as fastener pull-through [8-11].

Banbury and Kelly [8] investigated the pull-through failure of carbon laminates manufactured using both plane weave and unidirectional prepregs. An experimental campaign was performed to study the influence of the different parameters on the pull-through failure, namely: the geometry of the fastener head, the thickness of the laminate, and the stacking sequence. It was observed 
that the failed specimens exhibit intralaminar damage similar to that shown in composite panels when a low-velocity impact is applied in the transversal direction. In fact, the damaged zones (intralaminar and interlaminar damage) are distributed conically with respect to the axis of the fastener.

Banbury et al. [9] performed numerical analysis to study the pull-through damage mechanism. The Finite Element (FE) analysis indicated that:

- shear stresses in the vicinity of the bolt head are responsible for the intralaminar matrix cracking in through-the-thickness direction;

- tensile in-plane stresses are responsible for the flexural deformation of the material in particular in low-modulus laminate;

- matrix cracking was observed to be the primary failure mechanism while delamination (caused by the high interlaminar shear and peel stress) was the secondary mechanism.

Moreover, a numerical procedure to simulate the progressive damage in the material was proposed. A progressive damage model together with the maximum principal strain criterion were used and a good agreement between the experiments and the numerical predictions, both in terms of failure load, damaged zones and damage mechanisms, was obtained.

Kelly and Hallström [10] performed an experimental and numerical investigation of a laminate subjected to transversal loads. Different geometries, materials and lay-ups were investigated. The damage onset was observed to occur at a load of approximately $20-30 \%$ of the failure load, and the different failure mechanism were identified. As mentioned in previous investigations [8], the damaged zones show both iterlaminar and intralaminar matrix cracking. A three-dimensional finite element method was proposed to predict the first-ply 
failure.

Elder et al. [11] proposed a simplified three-dimensional finite elements model to model pull-through failure of composite laminates. It was concluded that simplified models allow to obtain a good prediction of the pull-through failure for quasi-isotropic laminates even if additional efforts are required to properly define the cohesive parameters used in the numerical model.

Fastener pull-through is particularly important for train structures where several hybrid connections are present:

- the connection between the main frame and the floor;

- the connection between the carbody shell and the top floor (in the case of a double deck carbody shell);

- the connection between the main frame and the carbody shell;

- the connection between the carbody shell and the roof.

Figure 1 represents the connection between the main frame and the side of the carbody shell. This connection uses two different materials because the internal panel cannot be toxic, while the external panel must have a good fire resistance [12]. For this reason, the internal panel is manufactured using phenolic resin, while the external panel is manufactured using vinylester resin.

[Fig. 1 about here.]

The aim of this paper is to experimentally study the fastener pull-through failure mode in GFRP laminates and to propose a numerical technique to predict the response of a bolted joints under out-of-planes loads. Taking into account that in industrial applications several resins are used to satisfy the current legislation (in particular about the fire behavior [12]) the study presented here 
concerns two different resins: phenolic and vinylester.

\section{Experiments}

\subsection{Materials}

The composites investigated in this study are:

- Fiber Glass-vinylester composite (GF-V);

- Fiber Glass-phenolic composite (GF-P).

The laminates were manufactured using the technique of resin infusion and they have the quasi-isotropic lay-up reported in Table 1. The mechanical properties of these laminates are reported in Table 2 where: $E_{i}$ is the Young's modulus in $i$ direction, $\nu_{i j}$ is the Poisson's ration in $i-j$ directions, $G_{i j}$ is the shear modulus in $i$ - $j$ directions, $X_{T}$ is the longitudinal tensile strength, $X_{C}$ is the longitudinal compressive strength, $Y_{T}$ is the transverse tensile strength, $Y_{C}$ is the transverse compressive strength, $S_{T}$ is the transverse shear strength, $S_{L}$ is the longitudinal shear strength and $\rho$ is the density.

The material was tested after a heat aging treatment according to the AFNOR norm [13].

[Table 1 about here.]

[Table 2 about here.] 


\subsection{Pull-through tests}

The pull-through test is performed following the norm ASTM D7332 - Standard Test Method for Measuring the Fastener Pull-Through Resistance of a Fiber-Reinforced Polymer Matrix Composite [14].

This test method proposes two procedures, A and B. Procedure A is used to enhance the fastener design while procedure B is used to study other design variables. Both procedures use flat test specimens with a circular hole in the center where the fastener is installed. In procedure A two specimens are joined using a fastener and one plate is rotated of $45^{\circ}$ with respect to the other. Each test specimen contains four additional holes at the corners where the fasteners are installed to connect the specimens to the test fixtures. In procedure B, the load is applied to the test specimen using a yoke as shown in Figure 2. Since procedure $\mathrm{A}$ is more complex and has inherent problems associated with the flexural stiffness of the specimen to test, procedure B was used.

[Fig. 2 about here.]

The test was conducted using an INSTRON-4208 test machine. Figure 3 shows the experimental set-up used. The test machine was equipped with a $100 \mathrm{kN}$ load cell. The speed of the machine (displacement controlled test) was $2 \mathrm{~mm} / \mathrm{min}$. The temperature of the room was $23^{\circ} \mathrm{C}$ and the relative humidity was $50 \%$ for all the duration of the tests.

[Fig. 3 about here.]

After each test the damaged specimen was examined and the type of failure was identified. 
The test results depend on Clearance Hole parameter $\left(C_{b}\right)$. This is the diameter of the plate that it is used in procedure $B$ of the test. In the tests performed $C_{b}$ was taken as $30 \mathrm{~mm}$. The dimensions of all test specimens, the ratio of the Clearance Hole Diameter $C_{b}$ to Fastener Hole Diameter $d$, and the ratio of the Fastener Hole Diameter to the thickness of the specimen $(h)$ are reported in the following points. The test specimens are square plates with a length of $105 \mathrm{~mm}$. Three specimens were tested for each configuration and for each material: one with a $6 \mathrm{~mm}$ diameter hole and the other with a $10 \mathrm{~mm}$ diameter hole. In the following, each specimen was indicated with the denomination PT-M-D where M indicates the material ( $\mathrm{P}$ for phenolic and $\mathrm{V}$ for vinylester) and $\mathrm{D}$ indicates the diameter in millimeters (6 or 10).

\subsection{Derived properties}

The load-displacement for a pull-through test is used to identify three important characteristics of the joints that are:

- the Initial Sub-Critical Failure Load: the load at the first sub-critical failure of the specimen;

- the Initial Sub-Critical Failure Displacement: the displacement at the first sub-critical failure of the specimen;

- the Failure Load: the maximum load attained in the test.

The specimen shows a first failure mode (generally delamination) at a relatively low load. After delamination, the specimen is able to support increasing loads. This point is identified in the curve by a load-drop, which is followed by a decrease of the stiffness of the test coupon. 


\subsection{GF-phenolic specimens}

Table 3 reports the dimensions of the specimens and the geometric parameters of the equipment used. Figure 4 shows the load vs. displacement curves for the phenolic specimens. The derived properties for the specimens tested are reported in Tables 4-5.

It should be noted that some specimens (see Tables 4-5) exhibited bolt failure. The bolts used for these tests were general purpose bolts (D933 8.8).

[Table 3 about here.]

[Table 4 about here.]

[Table 5 about here.]

[Fig. 4 about here.]

\subsection{GF-vinylester specimens}

Table 6 reports the dimensions of the specimens and the geometric parameters of the equipment used. Figure 5 shows the load vs. displacement curves for vinylester specimens. The derived properties for the specimens tested are reported in Tables 7-8.

[Table 6 about here.]

[Table 7 about here.]

[Table 8 about here.] 
[Fig. 5 about here.]

\subsection{Damaged zones}

Figure 6 shows the photos of a specimen tested up to failure. Both sides of the specimen are visible. The bottom side, Figure 6(b), shows delamination near the hole. As explained before, delamination occurs at the begin of the test when the load is relatively low (initial sub-critical failure). If the load increases, the intralaminar fracture in the material starts and, at the end, the specimen is totally penetrated by the washer. The delamination occurs abruptly when the sub-critical initial load is reached. It is not possible to exactly identify the location of the first delamination, even if it seems plausible that they occur at the interface with the thick $0^{\circ}$ plies due to the high interlaminar stresses promoted by the thick plies.

[Fig. 6 about here.]

\subsection{Comparison of the PT test results}

Figure 7 shows the failure loads of the two materials tested. As expected, increasing the hole diameter increases both the initial sub-critical failure load and the final failure load of the specimens. The results indicate that the two materials tested exhibit only slight differences in the values of the two failure loads considered.

It should be also noted that increasing the diameter also increases the ratio between the initial sub-critical failure load to the ultimate failure load. 
This means that larger holes exhibit an initial sub-critical failure load that is relatively lower when compared to the ultimate failure load.

The load corresponding to the first load-drop will be taken as the design load. This load corresponds to the onset of delamination that is likely to propagate under fatigue loading.

[Fig. 7 about here.]

\section{Numerical model}

Based on the previous remarks, a numerical model, based on the Finite Element Method, is developed to predict the delamination onset load. This load is taken as the design load.

\subsection{Numerical Implementation}

The Finite Element model was created using Abaqus 6.8 [15]. The mesh is shown in Figure 8. The specimen and the bolt (screw and washers) are represented as deformable bodies, while the steel plate used for the pull-through test is modeled as an analytical rigid surface. Frictionless contact is considered between the different parts. Figure 9 shows the FE model as viewed from the bottom.

[Fig. 8 about here.]

[Fig. 9 about here.] 
The test specimen, shown in Figure 10, was modeled using 8-nodes linear brick reduced integration elements (CRD8R) with a typical element size of $1 \mathrm{~mm}$.

Cohesive finite eelements, implemented as an Abaqus Users'subroutines (UMAT) [15], are used to predict delamination. These elements are used in all interfaces between plies with different fiber orientation angles.

The detailed definition of the cohesive model is presented in [16]. For the sake of completeness, the main aspects of the constitutive model are outlined in the following paragraphs.

The relation between the tractions transferred along a bridged crack, $\tau$, and the corresponding displacement jumps, $\boldsymbol{\Delta}$, reads:

$$
\tau_{i}=(1-\mathrm{d}) k \Delta_{i}-\left[\delta_{i 3} \mathrm{~d} k\left\langle-\Delta_{3}\right\rangle\right]
$$

where $\mathrm{d}$ is a scalar damage variable and $k$ is the penalty stiffness. The displacement jump $\Delta_{3}$ is related to mode I, whereas the displacement jumps $\Delta_{1}$ and $\Delta_{2}$ are related to shear modes of loading.

The operator $\langle x\rangle$ is defined as $\langle x\rangle=\frac{1}{2}(x+|x|)$, and $\delta_{i j}$ is the Kroenecker delta.

Introducing $\lambda$ as the norm of the displacement jump:

$$
\lambda=\sqrt{\left\langle\Delta_{3}\right\rangle^{2}+\Delta_{s h}^{2}}, \Delta_{s h}=\sqrt{\left(\Delta_{1}\right)^{2}+\left(\Delta_{2}\right)^{2}}
$$

The damage activation function for general mixed-mode loading is defined as:

$$
\mathcal{F}(\Delta, \mathrm{d})=\mathcal{L}(\Delta)-\mathrm{d} \leq 0
$$


where:

$$
\mathcal{L}(\boldsymbol{\Delta})=\min \left\{\frac{\Delta^{f}\left(\lambda-\Delta^{o}\right)}{\lambda\left(\Delta^{f}-\Delta^{o}\right)}, 1\right\}
$$

and:

$$
\mathrm{d}_{t}=\max \left\{0, \max _{s}\left[\mathcal{L}\left(\boldsymbol{\Delta}_{t}\right)\right]\right\}, 0 \leq s \leq t, \forall t \geq 0
$$

The displacement jumps corresponding to delamination onset $\left(\Delta^{o}\right)$ and to delamination propagation $\left(\Delta^{f}\right)$ under mixed-mode conditions are obtained using the Benzeggagh and Kenane criterion [17] for delamination propagation under mixed-mode loading, yielding [16]:

$$
\begin{gathered}
\Delta^{o}=\left\{\left(\Delta_{3}^{o}\right)^{2}+\left[\left(\Delta_{s h}^{o}\right)^{2}-\left(\Delta_{3}^{o}\right)^{2}\right] B^{\eta}\right\}^{1 / 2} \\
\Delta^{f}=\frac{1}{\Delta^{o}}\left[\Delta_{3}^{o} \Delta_{3}^{f}+\left(\Delta_{s h}^{o} \Delta_{s h}^{f}-\Delta_{3}^{o} \Delta_{3}^{f}\right) B^{\eta}\right]
\end{gathered}
$$

where $\eta$ is the mixed-mode interaction parameter used in the Benzeggagh and Kenane criterion [17] and $B$ is a local mixed-mode ratio defined as:

$$
B=\frac{\mathcal{G}_{s h}}{\mathcal{G}_{s h}+\mathcal{G}_{I}}=\frac{\Delta_{s h}^{2}}{\lambda^{2}}
$$

$\Delta_{3}^{o}$ and $\Delta_{\text {sh }}^{o}$ are respectively the displacement jumps corresponding to delamination onset in mode I and in shear mode: 


$$
\Delta_{3}^{o}=\frac{\tau_{3}^{o}}{k} ; \Delta_{s h}^{o}=\frac{\tau_{s h}^{o}}{k}
$$

where $\tau_{3}^{o}$ and $\tau_{s h}^{o}$ are the pure mode interlaminar strengths.

$\Delta_{3}^{f}$ and $\Delta_{s h}^{f}$ are respectively the displacement jumps corresponding to delamination propagation under mode I and in shear mode:

$$
\Delta_{3}^{f}=\frac{2 \mathcal{G}_{I c}}{\tau_{3}^{o}} ; \Delta_{s h}^{f}=\frac{2 \mathcal{G}_{I I c}}{\tau_{s h}^{o}}
$$

To reduce the complexity of the model (and the time needed for the analysis) the cohesive elements were used only in the vicinity of the bolt as shown in Figure 10.

[Fig. 10 about here.]

The relevant parameters for the definition of the cohesive elements are obtained using experimental data previously measured for a similar material [18]. The material properties used are shown in Table 9 .

[Table 9 about here.]

Using these values the exponent for the B-K criterion [17] is calculated using the least-squares method as $\eta=1.98$. The penalty stiffness, $k$, is taken as $10^{6} \mathrm{~N} / \mathrm{mm}^{3}$. The interface strengths are calculated using the engineering solution proposed by Turon et al. [19] resulting in $\tau_{3}^{o}=28.8 \mathrm{MPa}$ and $\tau_{s h}^{o}=$ 48.8MPa. 


\subsection{Numerical results}

Taking into account that no major differences were found between the delamination onset loads for the two materials tested, the numerical simulations are conducted only for the GF-P specimens.

Figure 11 shows the load-displacement relation predicted by the numerical model. The predictions for the initial sub-critical failure load and the experimental values are reported in Table 10. A reasonable agreement between the numerical predictions and the experimental data is obtained. The maximum error, $-10 \%$, is obtained for the PT-P-10 specimen. It is also observed that the load-drop identified in the experiments is also captured by the numerical model.

[Fig. 11 about here.]

[Table 10 about here.]

\section{Concluding remarks}

An experimental and a numerical study of the pull-through damage in GFRP laminates is presented in this paper. Two different material system (GFphenolic and GF-vinylester) and two geometries (diameter of the hole $6 \mathrm{~mm}$ and $10 \mathrm{~mm})$ are investigated. It is concluded that:

- increasing the diameter of the bolt increases both the sub-critical initial failure load and the failure load;

- larger holes exhibit a sub-critical initial failure load that is relatively lower 
when compared to the ultimate failure load;

- the interlaminar damage is the predominant phenomenon for damage onset;

- using three-dimensional finite element models using linear elastic elements together with cohesive elements it is possible to predict the value of the sub-critical initial failure load with a reasonable accuracy.

\section{Acknowledgements}

The first author acknowledges the financial support of the European Commission under Contract No. MRTN-CT-2005-019198.

\section{References}

[1] Catalanotti, G. Multi-material joints for high-speed train structures, PhD thesis, University of Porto, 2011.

[2] Comparaison entre caisses à technologie différent. Alstom Transport. 2008. (in French).

[3] Camanho, P.P. and Matthews, F.L., Stress analysis and strength prediction in FRP: a review, Composites - Part A. 1997; 28:529-547.

[4] Thoppul, S.D., Finegan, J., Gibson, R.F., Mechanics of mechanically fastened joints in polymer-matrix composite structures A review, Composites Science and Technology. 2009; 69:301-329.

[5] Hart-Smith, L.J., Mechanically-Fastened Joints for Advanced CompositesPhenomenological Considerations and Simple Analysis, Douglas Paper. McDonnell Douglas Corporation 1978; 6748:1-32.

[6] Hart-Smith, L.J., Design and Analysis of Bolted and Riveted Joints in Fibrous 
Composite Structures, Douglas Paper. McDonnell Douglas Corporation 1986; 1986:1-15.

[7] Camanho, P.P., Lambert, M., A design methodology for mechanically fastened joints in laminated composite materials, Composites Science and Tecnology. 2006; 66:3004-3020.

[8] Banbury, A., Kelly, D.W., A study of fastener pull-through failure of composite laminates. Part 1: Experimental, Composite Structures. 1999; 45:241-254.

[9] Banbury, A., Kelly, D.W., Jain, L.K., A study of fastener pull-through failure of composite laminates. Part 2: Failure prediction, Composite Structures. 1999; $45: 255-270$.

[10] Kelly, G., Hallström, S., Strength and failure mechanisms of composite laminates subject to localised transverse loading, Composite Structures. 2005; 69:301-314.

[11] Elder, D.J., Verdaasdonk, A.H., Thomson, R.S., Fastener pull-through in a carbon fibre epoxy composite joint, Composite Structures. 2008; 86:291-298.

[12] French Norm NF F 16-101:1988. All vehicles - the burning behavior - materials to choose. 1998, October (original in French).

[13] French Norm NF T 57-107:1986. Glass-fibre-reinforced plastics - Measurement of the change of characteristics during hot water treatment. 1986, December (original in French).

[14] ASTM D7332 / D7332M - 09, Standard Test Method for Measuring the Fastener Pull-Through Resistance of a Fiber-Reinforced Polymer Matrix Composite.

[15] Abaqus 6.8 Documentation, Dessault Systèmes. 2008. 
[16] Turon, A., Camanho, P.P., Costa, J., Dávila, C.G., A damage model for the simulation of delamination in advanced composites under variable-mode loading, Mechanics of Materials. 2006; 38:1072-1089.

[17] Benzeggagh, M.L., Kenane, M., Measurement of mixed-mode delamination fracture toughness of unidirectional glass/epoxy composites with mixed-mode bending apparatus, Composite Science and technology. 1996; 56:439-449.

[18] Tumino, D., Catalanotti, G., Cappello, F., Zuccarello, B., Experimental tests on fatigue induced delamination in GFRP and CFRP laminates, Experimental Analysis of Nano and Engineering Materials and Structures: Proceedings of ICEM13, Alexandropulis, Greece, July1-6, 2007.

[19] Turon, A., Camanho, P.P., Costa, J., Renart, J., Accurate simulation of delamination growth under mixed-mode loading using cohesive elements: Definition of interlaminar strengths and elastic stiffness, Composite Structures. 2010; 92:1857-1864. 


\section{List of Figures}

1 Hybrid connection 19

2 ASTM D7332 - Procedure B 20

3 Equipment set-up for PT test 21

4 Pull-through test; load vs. displacement for GF-phenolic specimens

5 Pull-through test; load vs. displacement for GF-vinylester specimens

$6 \quad$ Pull-through specimens after loading 24

$7 \quad$ Comparison of PT tests failure loads 25

$8 \quad$ FE model of the pull-through test (top view). 26

$9 \quad$ FE model of the pull-through test (bottom view). 27

10 FE model, elastic and cohesive elements (in red). 28

11 Predicted load vs. displacement curves. 29 


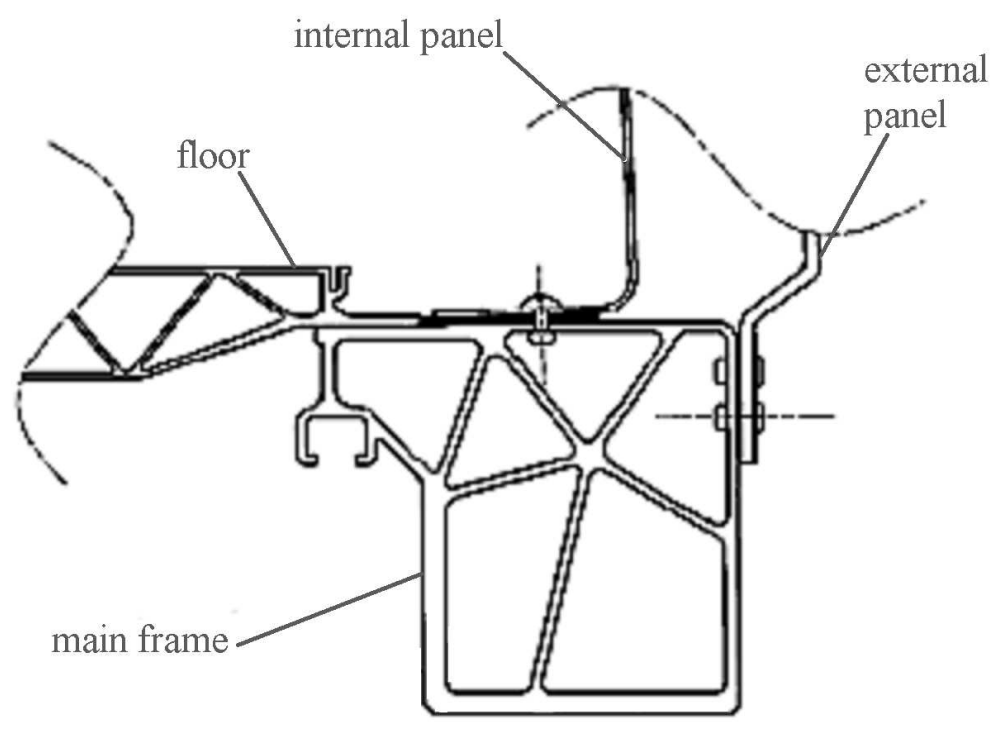

Fig. 1. Hybrid connection 

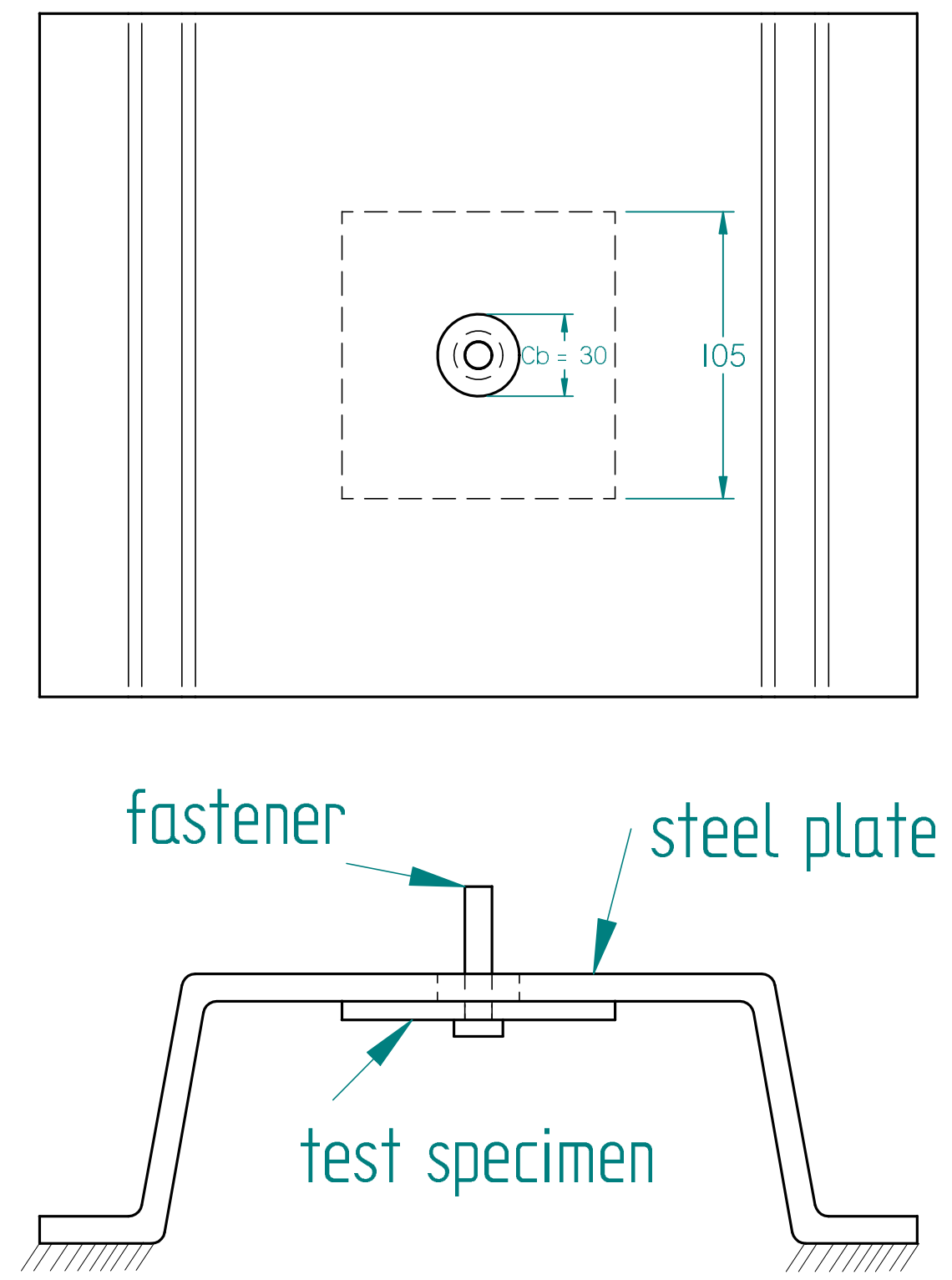

Fig. 2. ASTM D7332 - Procedure B 


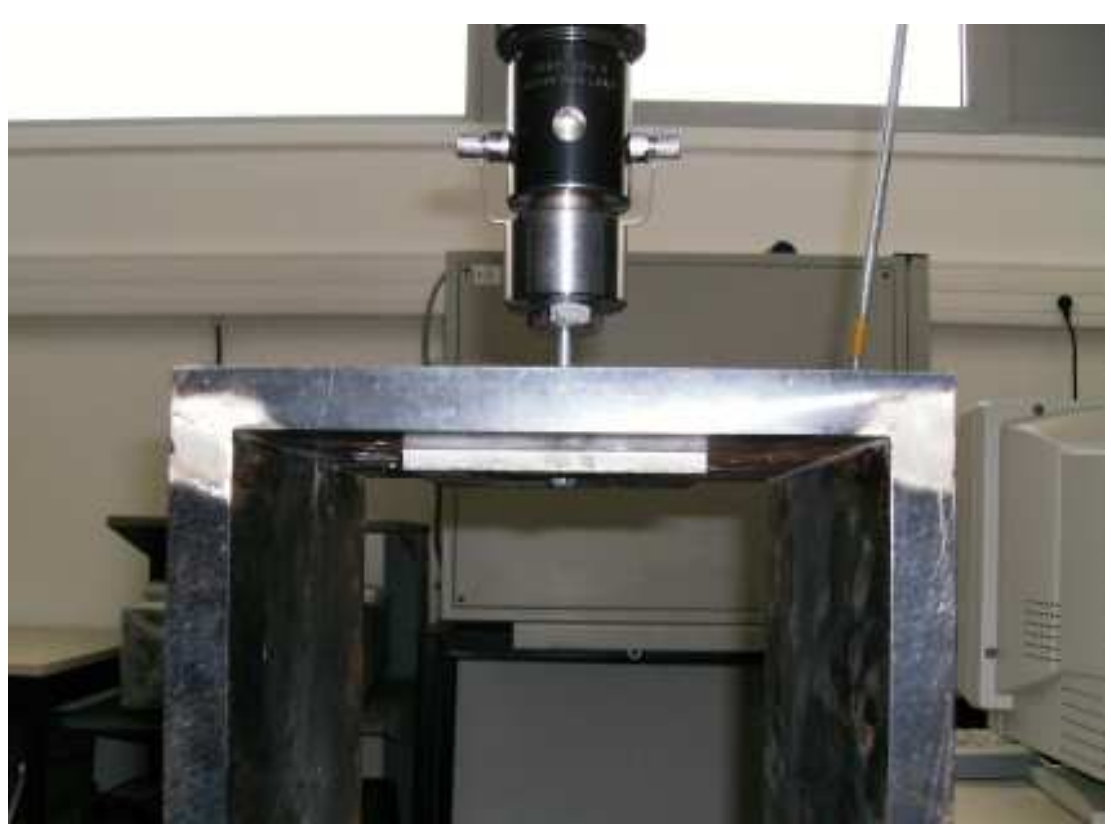

Fig. 3. Equipment set-up for PT test 


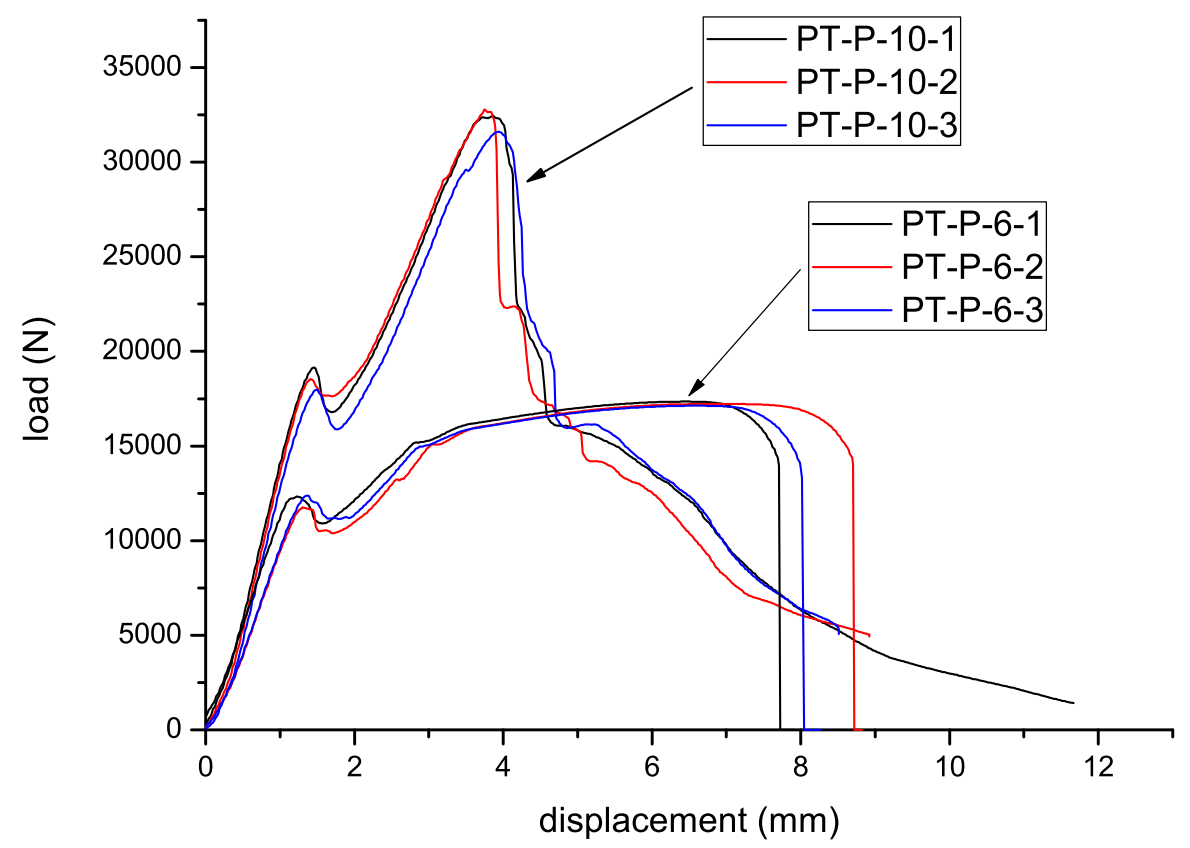

Fig. 4. Pull-through test; load vs. displacement for GF-phenolic specimens 


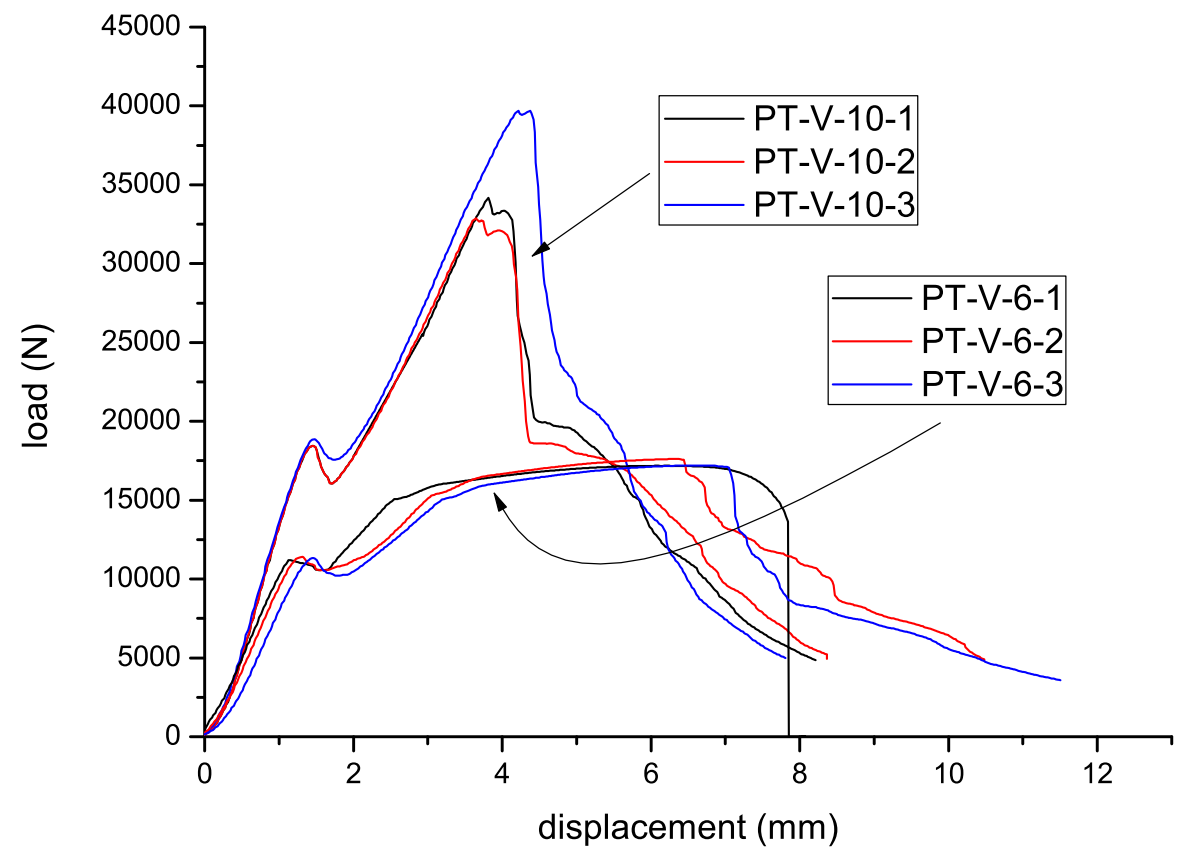

Fig. 5. Pull-through test; load vs. displacement for GF-vinylester specimens 


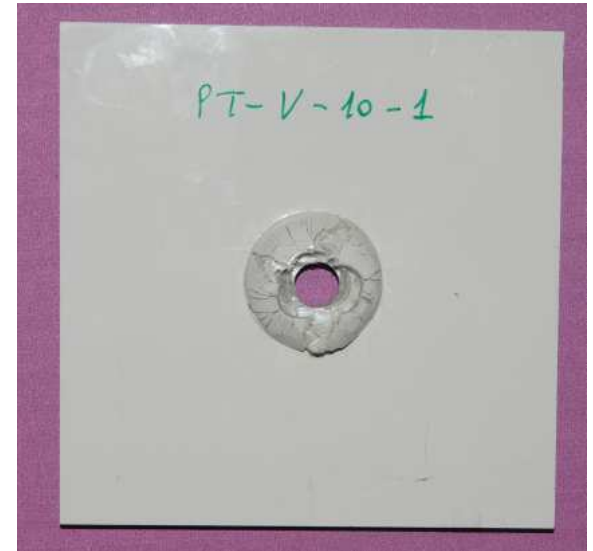

(a) intralaminar fracture

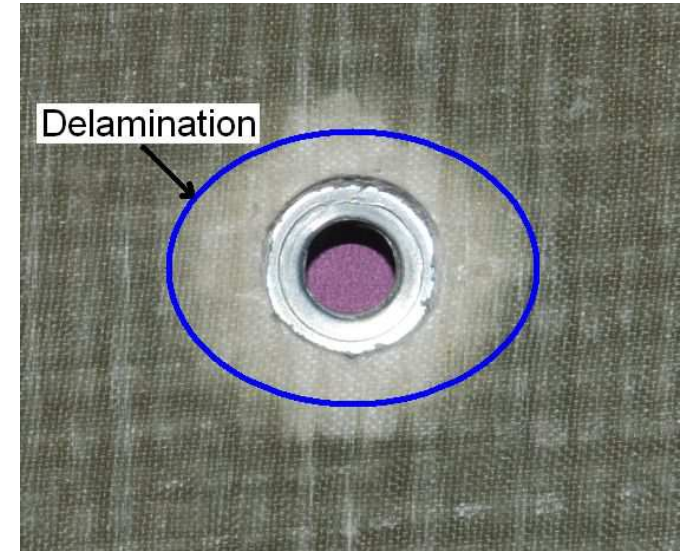

(b) delamination at sub-critical failure

Fig. 6. Pull-through specimens after loading 


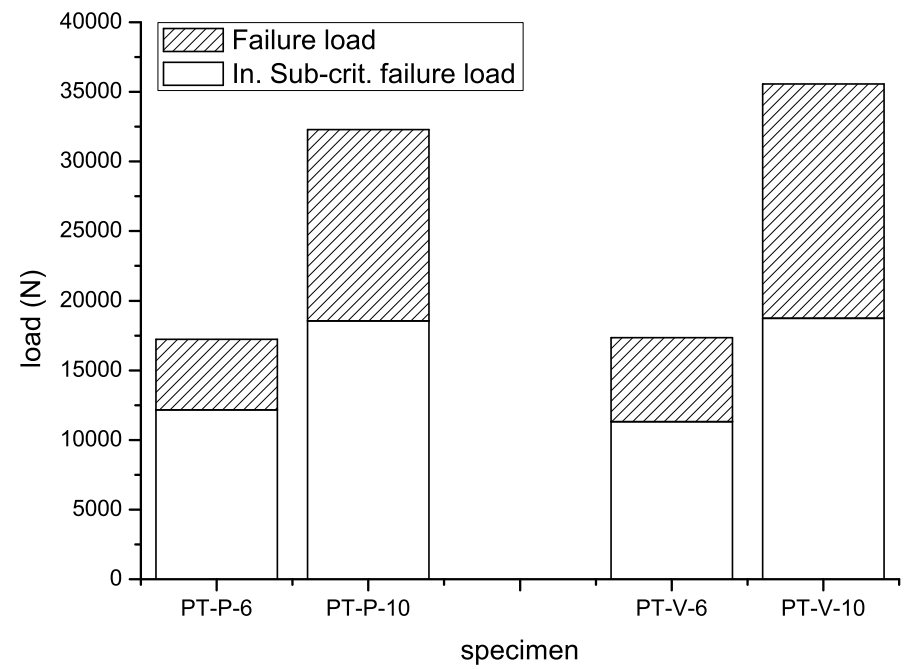

Fig. 7. Comparison of PT tests failure loads 


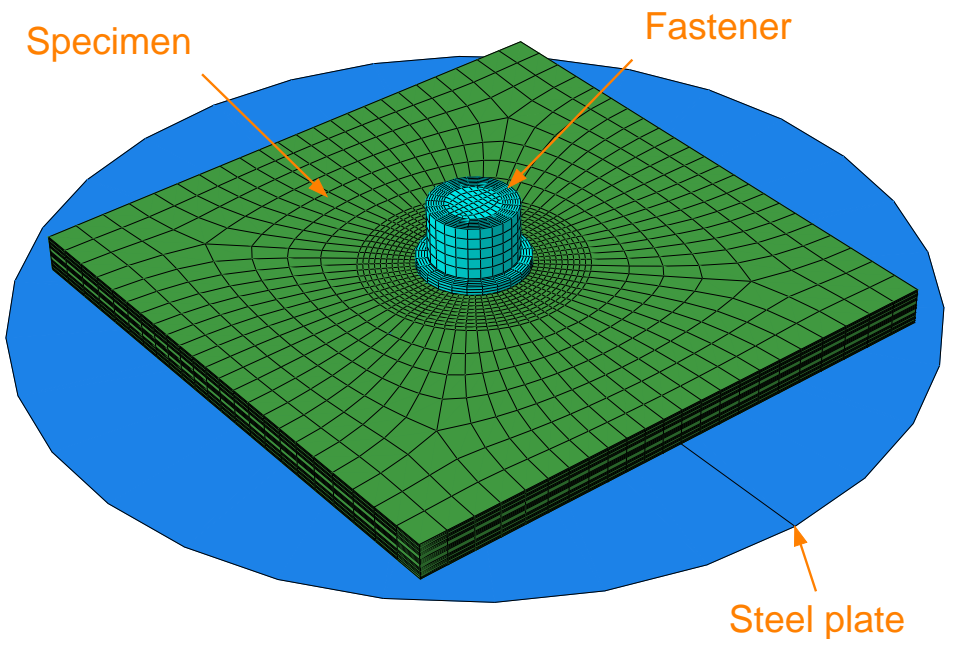

Fig. 8. FE model of the pull-through test (top view). 


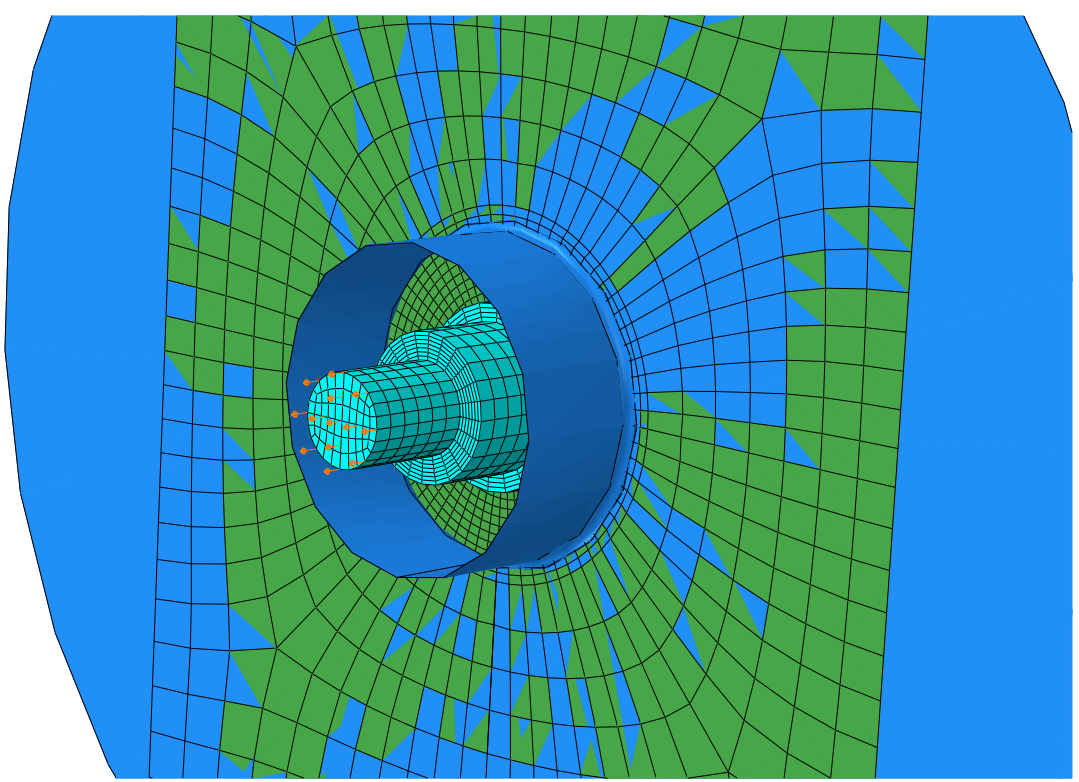

Fig. 9. FE model of the pull-through test (bottom view). 


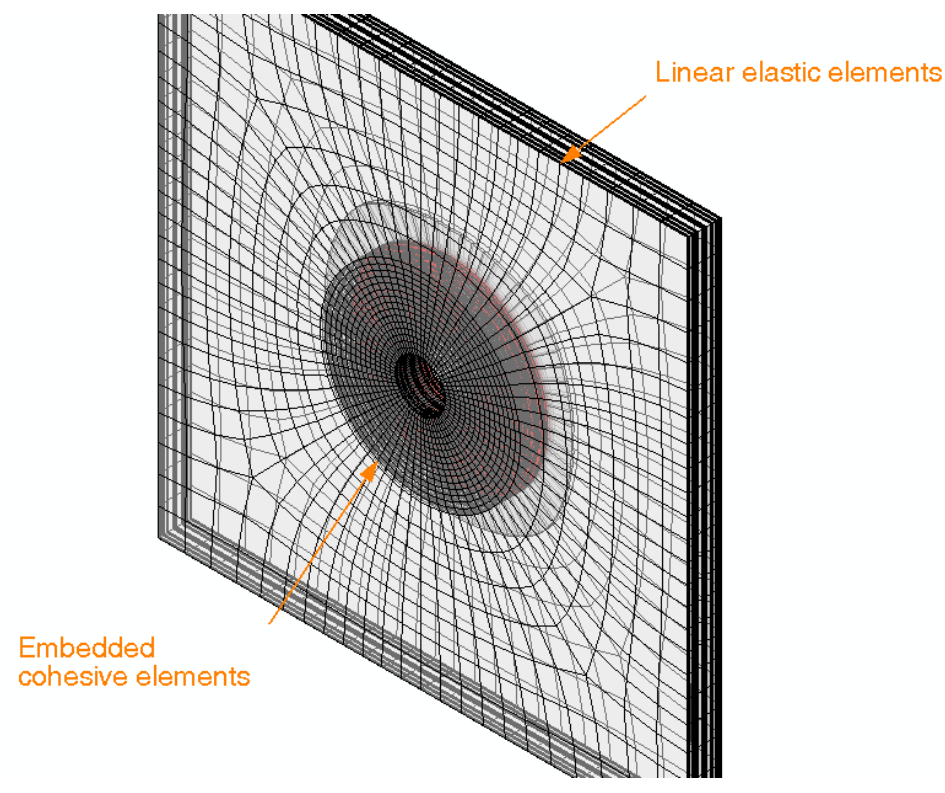

Fig. 10. FE model, elastic and cohesive elements (in red). 


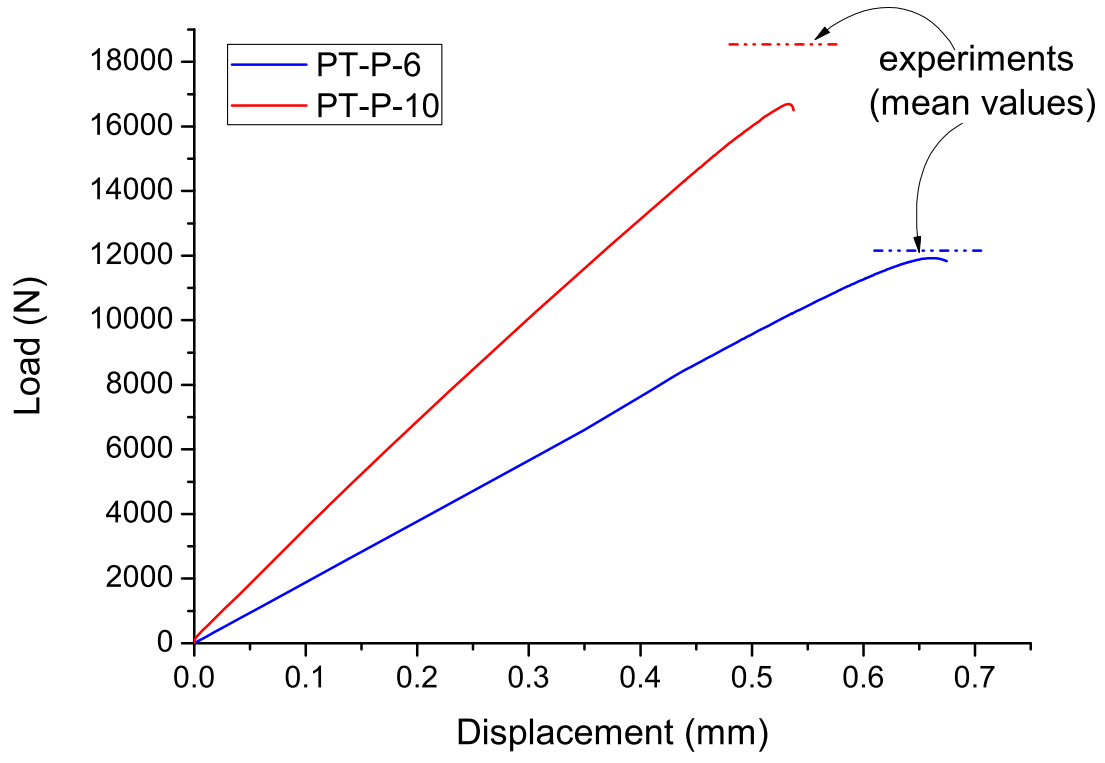

Fig. 11. Predicted load vs. displacement curves. 


\section{List of Tables}

1 Orientation pattern for GF-vinylester / phenolic composite. 31

$2 \quad$ Mechanical properties of GF-V and GF-P UD laminate. 32

3 GF-P specimens' dimensions. 33

4 Pull-through test, results for PT-P-6 specimens. 34

$5 \quad$ Pull-through test, results for PT-P-10 specimens. 35

$6 \quad$ GF-V specimens' dimensions. 36

$7 \quad$ Pull-through test, results for PT-V-6 specimens. 37

$8 \quad$ Pull-through test, results for PT-V-10 specimens. 38

$9 \quad$ Critical values of SERR (N/mm) [18]. 39

10 Initial sub-critical failure load: experiments and predictions. $\quad 40$ 
Table 1

Orientation pattern for GF-vinylester / phenolic composite.

\begin{tabular}{cccc}
\hline \hline ply & type of product & name & supplier \\
\hline 14 & $\pm 45^{\circ}-610 \mathrm{~g} / \mathrm{m}^{2}$ & EBX 600 & SELCOM \\
13 & $90^{\circ}-600 \mathrm{~g} / \mathrm{m}^{2}$ & roving UD 600 CHOMARAT & GAZECHIM \\
12 & $\pm 45^{\circ}-610 \mathrm{~g} / \mathrm{m}^{2}$ & EBX 600 & SELCOM \\
11 & $90^{\circ}-600 \mathrm{~g} / \mathrm{m}^{2}$ & roving UD 600 CHOMARAT & GAZECHIM \\
10 & $\pm 45^{\circ}-610 \mathrm{~g} / \mathrm{m}^{2}$ & EBX 600 & SELCOM \\
9 & $0^{\circ}-1246 \mathrm{~g} / \mathrm{m}^{2}$ & UNIE 1200 & SELCOM \\
8 & $\pm 45^{\circ}-610 \mathrm{~g} / \mathrm{m}^{2}$ & EBX 600 & SELCOM \\
7 & $\pm 45^{\circ}-610 \mathrm{~g} / \mathrm{m}^{2}$ & EBX 600 & SELCOM \\
6 & $0^{\circ}-1246 \mathrm{~g} / \mathrm{m}^{2}$ & UNIE 1200 & SELCOM \\
5 & $\pm 45^{\circ}-610 \mathrm{~g} / \mathrm{m}^{2}$ & EBX 600 & SELCOM \\
4 & $90^{\circ}-600 \mathrm{~g} / \mathrm{m}^{2}$ & roving UD 600 CHOMARAT & GAZECHIM \\
3 & $\pm 45^{\circ}-610 \mathrm{~g} / \mathrm{m}^{2}$ & EBX 600 & SELCOM \\
2 & $\pm 90^{\circ}-600 \mathrm{~g} / \mathrm{m}^{2}$ & roving UD 600 CHOMARAT & GAZECHIM \\
1 & $\pm 45^{\circ}-610 \mathrm{~g} / \mathrm{m}^{2}$ & EBX 600 & SELCOM \\
isoftalic poliester gelcoat & GCI S90000 VM10 SAF 1 & POLYPROCESS \\
\hline \hline
\end{tabular}


Table 2

Mechanical properties of GF-V and GF-P UD laminate.

\begin{tabular}{ccc}
\hline \hline materials & GF-vinylester & GF-phenolic \\
\hline$E_{1}(\mathrm{MPa})$ & 42830 & 35200 \\
$E_{2}=E_{3}(\mathrm{MPa})$ & 1530 & 3000 \\
$\nu_{12}$ & 0.35 & 0.35 \\
$\nu_{13}=\nu_{23}$ & 0.3 & 0.3 \\
$G_{12}(\mathrm{MPa})$ & 2800 & 3400 \\
$G_{13}=G_{23}(\mathrm{MPa})$ & 2800 & 3400 \\
$X_{T}(\mathrm{MPa})$ & 350 & 355 \\
$Y_{T}=Z_{T}(\mathrm{MPa})$ & 35 & 35 \\
$X_{C}(\mathrm{MPa})$ & 300 & 300 \\
$Y_{C}=Z_{C}(\mathrm{MPa})$ & 30 & 30 \\
$S_{T}(\mathrm{MPa})$ & 10 & 19 \\
$S_{L}(\mathrm{MPa})$ & 22 & 14 \\
$\rho\left(\mathrm{kg} / \mathrm{m}^{3}\right)$ & 1863 & 1900 \\
\hline \hline
\end{tabular}


Table 3

GF-P specimens' dimensions.

\begin{tabular}{lcccc}
\hline \hline Specimen & $\begin{array}{c}\text { Diameter } \\
(\mathrm{mm})\end{array}$ & $C_{b} / D$ & $h$ & $D / h$ \\
& $(\mathrm{~mm})$ & \\
\hline PT-P-6-1 & 6 & 5 & 6.80 & 0.882 \\
PT-P-6-2 & 6 & 5 & 6.80 & 0.882 \\
PT-P-6-3 & 6 & 5 & 6.80 & 0.882 \\
\hline PT-P-10-1 & 10 & 3 & 6.60 & 1.515 \\
PT-P-10-2 & 10 & 3 & 6.80 & 1.471 \\
PT-P-10-3 & 10 & 3 & 6.50 & 1.538 \\
\hline \hline
\end{tabular}


Table 4

Pull-through test, results for PT-P-6 specimens.

\begin{tabular}{lccc}
\hline \hline Specimen & $\begin{array}{c}\text { In. Sub-crit. failure load } \\
(\mathrm{N})\end{array}$ & $\begin{array}{c}\text { Failure load } \\
(\mathrm{N})\end{array}$ & $\begin{array}{c}\text { In. Sub-crit. failure displ. } \\
(\mathrm{mm})\end{array}$ \\
\hline PT-P-6-1 $\left(^{*}\right)$ & 12340 & 17348 & 1.228 \\
PT-P-6-2 $\left(^{*}\right)$ & 11752 & 17236 & 1.301 \\
PT-P-6-3 $\left(^{*}\right)$ & 12384 & 17132 & 1.360 \\
\hline Average & 12158 & 17238 & 1.296 \\
STDV & 352 & 108 & 0.066 \\
\hline \hline
\end{tabular}

(*) bolt failure 
Table 5

Pull-through test, results for PT-P-10 specimens.

\begin{tabular}{lccc}
\hline \hline Specimen & $\begin{array}{c}\text { In. Sub-crit. failure load } \\
(\mathrm{N})\end{array}$ & $\begin{array}{c}\text { Failure load } \\
(\mathrm{N})\end{array}$ & $\begin{array}{c}\text { In. Sub-crit. failure displ. } \\
(\mathrm{mm})\end{array}$ \\
\hline PT-P-10-1 & 19140 & 32460 & 1.462 \\
PT-P-10-2 & 18528 & 32780 & 1.403 \\
PT-P-10-3 & 17976 & 31608 & 1.492 \\
\hline Average & 18548 & 32282 & 1.452 \\
STDV & 582 & 605 & 0.045 \\
\hline \hline
\end{tabular}


Table 6

GF-V specimens' dimensions.

\begin{tabular}{lcccc}
\hline \hline Specimen & $\begin{array}{c}\text { Diameter } \\
(\mathrm{mm})\end{array}$ & $C_{b} / D$ & $h$ & $D / h$ \\
& $(\mathrm{~mm})$ & \\
\hline PT-V-6-1 & 6 & 5 & 7.00 & 0.857 \\
PT-V-6-2 & 6 & 5 & 7.15 & 0.839 \\
PT-V-6-3 & 6 & 5 & 6.80 & 0.882 \\
\hline PT-V-10-1 & 10 & 3 & 7.00 & 1.429 \\
PT-V-10-2 & 10 & 3 & 6.70 & 1.493 \\
PT-V-10-3 & 10 & 3 & 7.20 & 1.389 \\
\hline \hline
\end{tabular}


Table 7

Pull-through test, results for PT-V-6 specimens.

\begin{tabular}{lccc}
\hline \hline Specimen & $\begin{array}{c}\text { In. Sub-crit. failure load } \\
(\mathrm{N})\end{array}$ & $\begin{array}{c}\text { Failure load } \\
(\mathrm{N})\end{array}$ & $\begin{array}{c}\text { In. Sub-crit. failure displ. } \\
(\mathrm{mm})\end{array}$ \\
\hline PT-V-6-1 $\left(^{*}\right)$ & 11200 & 17184 & 1.127 \\
PT-V-6-2 & 11404 & 17624 & 1.315 \\
PT-V-6-3 & 11340 & 17204 & 1.463 \\
\hline Average & 11314 & 17337 & 1.302 \\
STDV & 104 & 248 & 0.168 \\
\hline \hline
\end{tabular}

(*) bolt failure 
Table 8

Pull-through test, results for PT-V-10 specimens.

\begin{tabular}{lccc}
\hline \hline Specimen & $\begin{array}{c}\text { In. Sub-crit. failure load } \\
(\mathrm{N})\end{array}$ & $\begin{array}{c}\text { Failure load } \\
(\mathrm{N})\end{array}$ & $\begin{array}{c}\text { In. Sub-crit. failure displ. } \\
(\mathrm{mm})\end{array}$ \\
\hline PT-V-10-1 & 18448 & 34172 & 1.447 \\
PT-V-10-2 & 18920 & 32864 & 1.440 \\
PT-V-10-3 & 18876 & 39692 & 1.477 \\
\hline Average & 18748 & 35576 & 1.455 \\
STDV & 260 & 3624 & 0.020 \\
\hline \hline
\end{tabular}


Table 9

Critical values of SERR (N/mm) [18].

\begin{tabular}{ccccc}
\hline \hline Mode mixity $\phi=\frac{\mathcal{G}_{I I}}{\mathcal{G}_{I}+\mathcal{G}_{I I}}$ & Test & $\mathcal{G}_{I c}^{\phi}$ & $\mathcal{G}_{I I c}^{\phi}$ & $\mathcal{G}_{c}$ \\
\hline 0 & DCB & 1.25 & 0 & 1.25 \\
0.25 & MMB & 1.14 & 0.38 & 1.52 \\
0.5 & MMB & 0.97 & 0.97 & 1.94 \\
0.75 & MMB & 0.6 & 1.81 & 2.41 \\
1 & ENF & 0 & 3.6 & 3.6 \\
\hline \hline
\end{tabular}


Table 10

Initial sub-critical failure load: experiments and predictions.

\begin{tabular}{cccc}
\hline \hline Specimens & Experimental value (N) & Numerical prediction (N) & Error (\%) \\
\hline PT-P-6 & 12158 & 11922 & $-2 \%$ \\
PT-P-10 & 18548 & 16700 & $-10 \%$ \\
\hline \hline
\end{tabular}

